\title{
ACADEMIC ADJUSTMENT AND SOCIO-ECONOMIC LEGACY EFFECTS: EVIDENCE FROM THE YEARS OF THE \#FEESMUSTFALL AND \#RHODESMUSTFALL PROTESTS
}

\author{
E. Papageorgiou* \\ School of Accountancy \\ e-mail: Elmarie.Papageorgiou@wits.ac.za / https://orcid.org/0000-0001-9356-6123
}

\section{W. Callaghan*}

Division of Human Resource Management and Management

School of Business Sciences

e-mail: chris.callaghan@wits.ac.za / https://orcid.org/0000-0002-6554-8363

*University of the Witwatersrand

Johannesburg, South Africa

\section{ABSTRACT}

South Africa's higher education sector experienced widespread protests during the years 2015 and 2016, associated with the \#FeesMustFall and\#RhodesMustFall movements. Using a sample of 1905 respondents, over these two years, structural equation models are used to test the contributions of academic adjustment to academic performance for first year accounting students, during the time of these protests. Three theoretical models are tested to explore the persistence of historically discriminatory legacy effects. No differences are found by ethnicity for the influence of academic adjustment difficulties on academic performance. Financially disadvantaged students are however found to be more vulnerable to the influence of financial disadvantage - those receiving financial aid score lower in assessments, and their academic performance seems to be vulnerable to the academic environment dimension of academic adjustment. It is concluded that historical legacy effects - at least insofar as they relate to student academic adjustment - may be limited to financial resource constraints. More concerted efforts on the part of university administrators and policy makers may be needed to improve the university environment and increase financial support for those who remain affected by historical socio-economic disadvantage.

Keywords: academic adjustment, student performance, SACQ, South Africa, students, university

\section{INTRODUCTION}

South Africa's higher education sector experienced widespread student protests during the years 2015 and 2016, primarily associated with the \#FeesMustFall movement. These protests called for free and decolonised education (Costandius et al. 2018). The \#FeesMustFall protests 
followed in the wake of the \#RhodesMustFall protests, the latter seeking to "bring into the open institutional racism in university life in South Africa and Britain, and to decolonize education" (Chaudhuri 2016, 1). The \#FeesMustFall movement created public awareness about higher education that is inadequately funded - the "proportion of student fees more than doubled over 13 years (from R7.8 billion to R17.8 billion), while government's contribution rose by 33\% (from R15.9 billion to R21.2 billion)" (Cloete 2015, 2; Badat 2016). What makes these increases particularly problematic is the fact that "tertiary education inflation is about $4 \%$ higher than the regular rate of inflation which has been at about 6\% per annum" (Poplak 2016).

Due to conditions of socio-economic deprivation, South Africa has some of the lowest graduation rates in the world (Letseka and Maile 2008). Thus, while ensuring pro-poor access to opportunity in the form of university entrance is one dimension of this important intervention, the need to ensure effective transition from school to university is another. Crucial to the successful transition of an individual into the university context is academic adjustment (Baker and Siryk 1999). Given the contextual imperatives associated with a resource-scarce context (Papageorgiou and Callaghan 2014; Papageorgiou et al. 2014) in which successful completion of accounting studies can be life changing, this article seeks to test theory that predicts how the academic adjustment of an individual contributes to student success, or accounting student performance, in the context of a large South African university. The objective of this study is therefore to develop knowledge to improve academic adjustment and better understand its influence on student performance in this context. The contribution this study seeks to make is arguably important, for the following reasons.

Firstly, lessons on diversity from South Africa offer valuable insights in an increasingly diverse global context. Since democracy, the student body has transformed racially, although its staff profile has yet to be fully transformed, a key issue brought to the forefront by the \#Feesmustfall protests (Jogee, Callaghan and Callaghan 2018). Secondly, given that academic adjustment is key to successful adjustment and performance for an individual (Baker and Siryk 1999), and given that diversity is at the heart of the adjustment process for students in this context (Jogee et al. 2018), knowledge of the diminishing consequence of ethnicity between academic adjustment and student performance is important. Any differences in this diminishing consequence would suggest aspects of the academic adjustment process that may continue to transmit discriminatory effects. Such knowledge would be useful in identifying what aspects of the academic adjustment mechanism are vulnerable to influence in this context at this time.

Given these relationships, and the context in which they play out, this study seeks, therefore, to ask the following research questions. (i) To what extent does ethnicity moderate the influence of academic adjustment on academic performance? (ii) To what extent does 
ethnicity and gender interact in their influence on academic performance, over and above the effects of academic adjustment? (iii) To what extent does age mediate the relationship between academic adjustment and academic performance? Three different structural equation models are constructed and tested to answer each of these research questions. Relevant literature and theory is now discussed.

\section{LITERATURE AND THEORY}

The link between academic adjustment and academic performance is important because students' academic performance is a dominant predictor of retention and graduation (Pascarella and Terenzini 1991; Boulter 2002). Prior research has investigated many factors influencing students' academic performance (Chansarkar and Michaeloudis 2001; Baard et al. 2010). Such studies have had a focus on different topics, such as, for example, those related to absenteeism (Schmulian and Coetzee 2011), attendance (Marburger 2010), parental style (Hickman, Bartholomae and McKenry 2000; Papageorgiou and Callaghan 2017), gender (Wally-Dima and Mbekomize 2013), absence of readiness and poor motivation (Boyle, Carter and Clark 2002; Ozga and Surhanandan 1998), as well as other institutional factors (Akenbor and Ibanichuka 2014). Given the importance of academic performance in this country to throughput and graduation, the contribution of academic adjustment to academic performance is of particular interest in this context. This study tests three different theoretical models. The first of these is considered as follows.

\section{Academic adjustment moderation effects}

Academic adjustment, as conceptualised by Baker and Siryk $(1999,14)$ relates to "a student's success in coping with the various educational demands characteristic of the college experience". These demands primarily fall into four categories. The first of these relates to motivation, or "attitudes toward academic goals and the academic work required, motivation for being in college and doing academic work, sense of educational purpose" (Baker and Siryk $1999,14)$. Given the high socioeconomic inequality and a history of inequality in access to opportunity in this context (Ballard, Habib and Valodia 2006), accountancy studies may offer important opportunities for many students to escape poverty. Individuals with higher motivation as a category of academic adjustment are expected to perform better. The stakes are perhaps higher for the previously disadvantaged for whom accountancy studies may represent a lifetime opportunity for socio-economic upliftment.

The second category relates to application, or "how well motivation is being translated into actual academic effort, how successfully the student is applying herself/himself to the 
academic work and meeting academic requirements" (Baker and Siryk 1999, 14). If motivation varies by ethnicity, and financial disadvantage can act as a motivator, then there might be differences in effort that derive from differences in motivation. However, it is unclear as to the extent these differences might persist in a context like accountancy studies where it needs to be acknowledged that all students require high motivation and application to have passed entry criteria into the course.

Baker and Siryk $(1999,14)$ define the third category of academic adjustment as "the efficacy of success of academic effort as reflected in various aspects of academic performance, the effectiveness of academic functioning", termed performance. To the extent that different ethnic groups may have experienced differential access to opportunity, financial disadvantage may persist. If so, through differential access to resources, certain groups might have different constraints to their performance due to resource scarcity (Papageorgiou and Callaghan 2014). Alternatively, motivational effort associated with the high stakes nature of accountancy studies might dominate resource constraints.

Adjusting to the university environment is an important predictor of academic performance (Petersen, Louw and Dumont 2009). Academic environment is Baker and Siryk's $(1999,14)$ fourth category, defined as "satisfaction with the academic environment and what it offers". This study sampled first year students over the years 2015 and 2016, a period which coincided with the \#FeesMustFall movement, a period of protest by students calling for free and decolonised education (Ngcoba, Manyathela and Bateman 2016). These protests reflected dissatisfaction on the part of students with the "colonial" characteristics of the country's universities and their primarily "Western" values and cultural climate (Manjra 2016; Pilane 2016). Dissatisfaction with the academic environment is expected to differ by ethnic group, but what is not clear here is the relationship between this dissatisfaction, as evidenced in the protests, and academic performance. On account of this literature, Hypothesis a is derived, that ethnicity moderates the influence of academic adjustment on performance.

Although apartheid discrimination in this context typically took the explicit form of racial discrimination, gender-related inequalities are also part of its legacy (Meyiwa et al. 2017). Over and above this legacy of unequal pay and work-related gender discrimination, the apartheid legacy of violence has also contributed to the country's degrees of gender-based violence, which are amongst the highest globally (Naidoo and Nadvi 2013). Given these legacy effects, the post-apartheid regime has prioritised gender-equality in its equity legislation, for example in the form of the "Constitution of the Republic of South Africa (Act 108 of 1996) (Act 108 of 1996)" (Meyiwa et al. 2017), the "Domestic Violence Act (Act 116 of 1998)", and the "Criminal Law (Sexual Offences and Related Matters) Amendment Act (32 of 2007)" (Naidoo 
and Nadvi 2013). This, and other related bodies of literature suggest that the experiences of women in this context may still reflect the apartheid legacy. As such, it is important to understand the extent to which student performance in this context has transcended these legacy issues. Given that gender differences in performance might not be independent of the country's discriminatory history, Hypothesis b is also offered, that ethnicity moderates the influence of gender on performance. This is tested as an interaction effect, as legacy effects such as those associated with gendered socio-economic disadvantage might be expected to be stronger according to ethnicity.

\section{Academic adjustment mediation effects}

According to Spaull (2012), the current education system in South Africa lacks the ability to educate most of the youth since the system is ineffective, inefficient and unfair, perpetuating socio-economic disadvantage associated with its history. Taking longer to finish schooling in this context might reflect legacy effects of socio-economic disadvantage According to the predictions of human capital theory (Becker 1964), experience can accumulate over time in the form of general human capital. Given different payoffs associated with different subject and career choices (Coldwell and Callaghan 2013), accountancy studies may offer a financially attractive career path in a resource constrained developing country context. It is unclear, however, how age may channel adjustment effects in this context. This channel might be positive or negative. However, if age is a channel through which academic adjustment vulnerabilities transmit to academic performance, this would warrant targeted support for older students to enable their academic adjustment. This would reflect a longer schooling tenure effect rather than an advantage associated with maturity. Knowledge of this difference is important in this context. Hypothesis $\mathrm{c}$ is therefore offered, that age mediates the influence of academic adjustment on performance.

To test these hypotheses, different SEM models are constructed. The first model, the confirmatory factor analysis model, utilises Baker and Siryk's (1999) full scale. The second is the modified measurement model. The third model is a structural model developed to test moderation relationships using critical ratios (Gaskin 2016). This approach is chosen as it provides a test of path invariance, and was therefore appropriate. The fourth model tests moderation through the inclusion of interaction terms. This approach is undertaken because it offers interaction plots that allow graphical representations of the interaction effects. The fifth model is developed to test the mediating effect of age on the contribution of the academic adjustment dimensions to student performance. These models are explained in the following sections. 


\section{METHODS}

The research method was quantitative, employing an electronic questionnaire (Bryman and Bell 2011) to collect data which was used to test the hypotheses that were derived above. The study is therefore concerned with theory testing; seeking to test three theoretical models using three models tested using SEM.

\section{Participants}

The sampling frame includes first-year accounting students registered for two courses over a period of two years, namely a Financial Accounting I course for the Bachelor of Commerce Degree in Accounting which students take on the Chartered Accountant (CA) stream and an Accounting I course for General Bachelor of Commerce Degree at a large South African university. Financial Accounting I had 643 registered students in 2015 and 680 students in 2016. Accounting I had 573 registered students in 2015 and 597 students in 2016. In all, the sampling frame comprised a total of 2493 first-year accounting students.

\section{Data collection}

Data was collected from two sources. Firstly, data to measure the dependent variable comprised student results for April and June assessments. The use of this process mitigated against common method bias, in that measures of the independent variables were collected from a different source than that of the dependent variable. Secondly, data was collected using an on-line electronic questionnaire. The "Student Adaption to College Questionnaire (SACQ)" was used to measure academic adjustment. This instrument is discussed as follows.

\section{Research instrument}

The SACQ, a self-report questionnaire (Baker and Siryk 1984; 1989) was used for measuring academic adjustment. Prior studies (Beyers and Goossens 2002; Sennett et al. 2003; Yazedjian, Toews and Navarro 2009; Love and Thomas 2014; Nyamayaro and Saravanan 2013) have used this instrument, demonstrating its reliability and validity in other contexts.

The questionnaire consists of five sections. Section 1 samples biographical data of students, including age, ethnicity, gender, and whether the student is on the "National Student Financial Aid Scheme (NSFAS)", which is a means tested loan programme, typically for financially disadvantaged students. The SACQ was adapted and the word "college" was replaced by "university", as "university" is more commonly used for higher education institutions in South Africa. Other questions were also adapted to accommodate the South 
African context. Sections 2 to 5 include statements concerning the adjustment of students to university. A 5-point Likert Scale, ranging from, "not at all true for me" to "very much true for me" was used. The same scale was used by earlier adjustments of the SACQ (Jou and Fukada 1995; Beyers and Goossens 2002) in comparison to the original 9-point scale used by Baker and Siryk (1989).

\section{Procedure}

All students received an invitation via the university portal to participate in the research. The university student portal was used to post the link to the questionnaire. The lecturers briefed the aim and contribution of the research and that their responses would be anonymous. Students provided their student number to link the questionnaire results to academic marks and were assured that the data would be reported anonymously at group level and not individually. Approval for ethics clearance was obtained from the university under review. Results are now reported and discussed.

\section{RESULTS AND DISCUSSION}

A total response rate of 76.41 per cent was obtained of 2493 students, with 1905 usable responses. This relatively high response rate allowed for a reasonably complete perspective of the descriptive characteristics of the population of first year accounting students in the classes Accounting 1 and Financial Accounting 1 across the two years. The use of these classes allowed for tests of adjustment to university in a first-year accounting context across almost all accounting students over the course of two years. Women are the majority, comprising 55 per cent of the sample. Out of the total, 9 per cent of the sample report being NSFAS recipients. NSFAS loans to students have increased over time (Letseka and Maile 2008), and provide financial loans to resource-constrained students. Of the academic adjustment items, self-report scores are the highest for motivation and lowest for performance adjustment.

Table 1: Descriptive statistics of demographics and other variables of respondents

\begin{tabular}{|l|c|c|c|c|}
\hline \multicolumn{1}{|c|}{ Variable } & Minimum & Maximum & Mean & Standard Deviation \\
\hline Age & 1 & 5 & 2.17 & 1.060 \\
\hline male & 0 & 1 & 0.45 & 0.497 \\
\hline Asian & 0 & 1 & 0.16 & 0.370 \\
\hline Black & 0 & 1 & 0.60 & 0.490 \\
\hline Coloured & 0 & 1 & 0.05 & 0.226 \\
\hline White & 0 & 1 & 0.14 & 0.347 \\
\hline NSFAS & 0 & 1 & 0.09 & 0.282 \\
\hline April marks & 11 & 100 & 66.14 & 14.916 \\
\hline
\end{tabular}




\begin{tabular}{|l|c|c|c|c|}
\hline \multicolumn{1}{|c|}{ Variable } & Minimum & Maximum & Mean & Standard Deviation \\
\hline June marks & 7 & 95 & 63.70 & 14.584 \\
\hline Motivation & 1 & 5 & 4.022 & 0.533 \\
\hline Application & 1 & 5 & 3.439 & 0.699 \\
\hline Performance & 1 & 5 & 3.067 & 0.695 \\
\hline Academic Environment & 1 & 5 & 3.679 & 0.695 \\
\hline
\end{tabular}

There were no systematic patterns in the missing data; these were taken to be missing completely at random. The deletion of missing data can be acceptable if missing at random (Schreiber et al. 2010), and case-wise deletion was performed.

\section{Tests of the assumptions of the statistical models}

The psychometric properties of the SACQ scale were first tested using a confirmatory factor analysis.

Table 2: Model Fit Statistics Full Sample (all ethnic groups included)

\begin{tabular}{|l|c|c|c|c|c|}
\hline & $\begin{array}{c}\text { Full } \\
\text { measurement } \\
\text { model }\end{array}$ & $\begin{array}{c}\text { Modified } \\
\text { measurement } \\
\text { model }\end{array}$ & Mediation & $\begin{array}{c}\text { Interaction } \\
\text { Moderation } \\
\text { Model }\end{array}$ & $\begin{array}{c}\text { Critical Ratio } \\
\text { Moderation } \\
\text { Model }\end{array}$ \\
\hline Chi-square & 2744.9 & 442.603 & 761.156 & 883.130 & 910.066 \\
\hline Degrees of freedom & 203 & 44 & 86 & 128 & 204 \\
\hline CMIN/DF & 13.522 & 10.059 & 8.851 & 6.899 & 4.461 \\
\hline AIC & 2844.878 & 510.603 & 861.156 & 1007.130 & 1114.066 \\
\hline ECVI & 1.494 & .268 & .452 & .529 & .584 \\
\hline CFI & .787 & .924 & .892 & .913 & .889 \\
\hline PCFI & .691 & .616 & .640 & .683 & .667 \\
\hline GFI & .855 & .962 & .952 & .953 & .946 \\
\hline AGFI & .819 & .932 & .923 & .930 & .918 \\
\hline RMSEA & .081 & .069 & .064 & .056 & .043 \\
\hline Mardia coefficient & 80.765 & 34.342 & 28.655 & 26.095 & 82.266 \\
\hline
\end{tabular}

Notes: "CMIN/DF: minimum discrepancy value; GFI: goodness of fit index; AGFI: adjusted goodness of fit model; CFI: comparative fit index; PCFI: parsimony adjusted comparative fit; RMSEA: root mean square error of approximation; AIC: Akaike information criterion (AIC); ECVI: expected cross-validation index (ECVI)".

As discussed previously, five models were tested. Table 2 includes three measures of absolute predictive fit measures, namely the minimum discrepancy value (CMIN/DF), the "Akaike information criterion (AIC)" and "Expected Cross-validation Index (ECVI)", a measure of comparative fit in the form of the "Comparative Fit Index (CFI)", a measure of parsimonious fit namely the "Parsimony-adjusted Comparative Fit Index (PCFI)", and other tests of general fit such as the "Goodness of Fit Index (GFI)", the "Adjusted Goodness of Fit Index (AGFI)", and the "Root Mean Square Error of Approximation (RMSEA)". The testing of the full measurement model provided a test of whether the full SACQ scale met the fit requirements to be used as a full scale in this context. The modified measurement model was modified to meet 
the minimum fit requirements for use as part of the structural model (Byrne 2010).

The Chi-squared values are significant in all models, but this is not considered problematic as this statistic is highly sensitive to sample size (Schreiber et al. 2010) and the models tested here have relatively large sample sizes. In terms of the absolute predictive fit measures, the Chisquared value of the CFA model (labelled as the full measurement model in the first column of Table 2), is 2744.9 with 203 degrees of freedom. The ratio of the Chi-squared value to the degrees of freedom, or minimum discrepancy value (CMIN/DF) is 13.522 (Table 2). This is greater than the value of 3 suggested by Wheaton et al. (1977), suggesting a less than ideal fit for the CFA-tested model in this context.

Information from the modification indices and from the standardised residual covariances was used to guide the modification process. When modifying the model, it was not possible to maximise the fit for a single sub-sample ethnic group within the sample without reducing the fit of another. Checks on the process were obtained by repeating certain modifications using a sample that included only Black and White sub-samples. The group function in AMOS was used to do this. This further testing revealed that different adjustments were necessary for these different groups, confirming the presence of heterogeneity bias in the measurement model.

At the end of the adjustment process (after modifications to the initial "full model"), however, a reasonable level of configural invariance was obtained, but only at the level needed to meet the basic, or minimum fit requirements for testing. In terms of the other absolute predictive fit measures, the "Akaike information criterion (AIC) and expected cross-validation index (ECVI) values" show an improvement for the modified model over the CFA-tested initial full model. These indices have no reference value, and can only be used to compare adjustments made to a model.

The comparative fit index value (CFI) is a comparative fit measure which compares the default model to the baseline (independence) model. The CFI value for the CFA-tested model is .787, which falls short of the ideal of .95 or higher (Schreiber et al. 2010). After modification, the CFA value rises to .924 , which is closer to the ideal. In terms of parsimonious fit indices, the PCFI value for the CFA-tested model is .691. The GFI fit value is .855 for the CFA-tested model, but after modifications, the measurement model has a value of .962, which is above the recommended value of .95 . The AGFI value for the CFA model is .819 but improves to .936 after modifications of the measurement model. The RMSEA value for the CFA model is .081, which is just over the threshold border of $<.06$ to .08 (Schreiber et al. 2010), but after modification this value improves to .069 , to within this threshold. On account of the modifications made to the initial model, the modified model was taken to reasonably meet the minimum fit requirements for the analysis of the measurement model. 
The Mardia coefficient has a critical ratio greater than 1.96, indicating the presence of multivariate non-normality. On the basis of this result, bootstrapping was used to obtain confidence intervals for the results that were robust to the influence of multivariate nonnormality. Bootstrapping was used in all testing, with 200 iterations.

Despite its successful use in other contexts (Baker and Siryk 1984; 1989; Beyers and Goossens 2002; Sennett et al., 2003; Yazedjian et al. 2009; Love and Thomas 2014; Nyamayaro and Saravanan 2013), the full SACQ scale items relating to academic adjustment are not found to perform adequately in this context without modification. Other studies in the area of accounting education should take cognisance of this finding, and should proceed with caution. Although the results presented here suggest that the scale can be modified to meet basic requirements for use, we recommend others develop the scale further to obtain a better fit with this context. South Africa is characterised by extreme diversity (Sennett et al., 2003), which is reflected in its eleven official languages (Nel et al. 2012). The diversity inherent in this context therefore has important implications for the testing of the psychometric properties of scales developed in other contexts.

\section{Hypothesis a: Ethnicity moderates the influence of academic adjustment on performance}

Figure 1 shows the structural model developed to test the moderating influence of societal disadvantage on student performance. Given the country's history, it was important to test whether ethnicity still has any legacy effects on the relationships between academic adjustment and student performance.

According to the results of the critical ratio tests of moderation (Table 3), in terms of ethnicity there is path invariance between the academic adjustment dimensions and student performance when the sample of Black students is tested against the rest of the cohort. None of the $\mathrm{z}$ scores indicates a significant difference. This result suggests that legacy effects of historical discrimination are not present in terms of the contributions of academic adjustment to academic performance.

There are, however, other potential legacy differences. Although there are no significant differences between groups, there are within-group differences. Of the academic adjustment dimensions, only academic environment is "positively and significantly associated with academic performance" $(\mathrm{p}<.036)$, and only so for Black students. This association is not significant for the rest of the cohort. This result suggests that academic performance might be sensitive to perceptions of the academic environment for Black students. Academic 


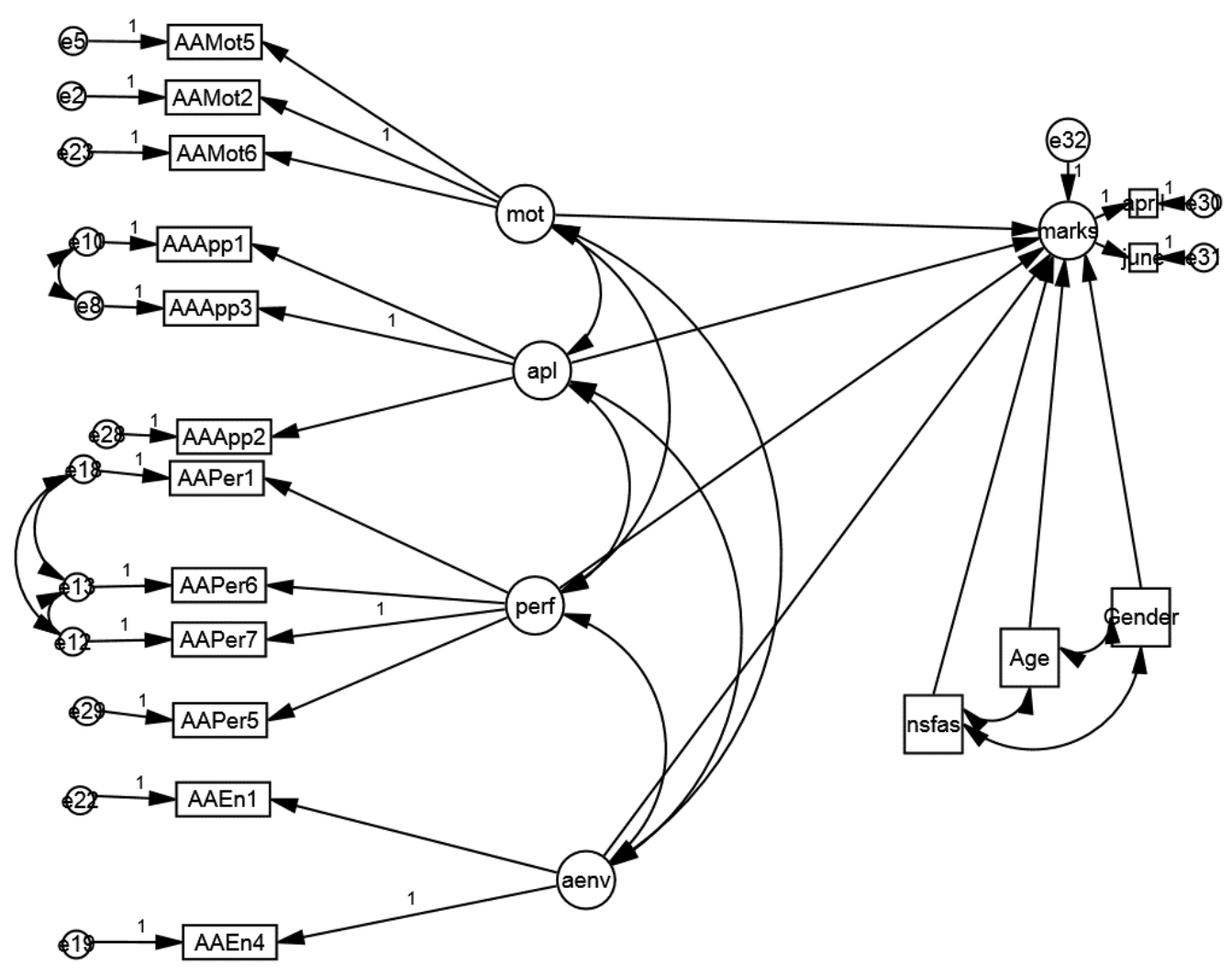

Notes. mot Motivation; apl Application; perf Performance; aenv Academic environment; marks Student performance

Figure 1: Critical ratio tests of the moderation effect of ethnicity on the relationship between academic adjustment and student performance

Table 3: Results of critical ratio tests of moderation (Black students)

\begin{tabular}{|c|c|c|c|c|c|c|c|}
\hline & & & \multicolumn{2}{|c|}{ Black } & \multicolumn{2}{|c|}{ Rest of the cohort } & \multirow{2}{*}{ z-score } \\
\hline & & & Estimate & $\mathbf{P}$ & Estimate & $\mathbf{P}$ & \\
\hline marks & $<---$ & mot & -2.671 & 0.574 & 4.016 & 0.520 & 0.853 \\
\hline marks & $<---$ & apl & 5.656 & 0.406 & 0.490 & 0.962 & -0.422 \\
\hline marks & $<--$ & perf & -4.302 & 0.567 & 2.115 & 0.843 & 0.492 \\
\hline marks & $<--$ & aenv & 2.524 & 0.036 & 0.313 & 0.806 & -1.260 \\
\hline marks & $<--$ & Age & -0.809 & 0.000 & -0.679 & 0.069 & 0.295 \\
\hline marks & <--- & male & -1.150 & 0.014 & -0.186 & 0.805 & 1.088 \\
\hline marks & $<--$ & nsfas & -1.889 & 0.022 & -0.916 & 0.736 & 0.343 \\
\hline AAMot5 & $<---$ & mot & 1.228 & 0.000 & 1.216 & 0.000 & -0.116 \\
\hline AAApp1 & <--- & apl & 0.798 & 0.000 & 0.840 & 0.000 & 0.478 \\
\hline AAPer6 & $<--$ & perf & 1.943 & 0.000 & 2.276 & 0.000 & 1.163 \\
\hline AAPer1 & $<---$ & perf & 0.725 & 0.000 & 0.651 & 0.000 & -0.645 \\
\hline AAEn1 & $<---$ & aenv & 0.735 & 0.000 & 0.801 & 0.000 & 0.526 \\
\hline AAMot6 & $<---$ & mot & 0.815 & 0.000 & 0.731 & 0.000 & -0.834 \\
\hline AAApp2 & $<---$ & apl & 1.107 & 0.000 & 1.245 & 0.000 & 1.153 \\
\hline AAPer5 & $<---$ & perf & 2.071 & 0.000 & 2.442 & 0.000 & 1.131 \\
\hline June & $<---$ & marks & 1.454 & 0.000 & 1.329 & 0.000 & -0.438 \\
\hline
\end{tabular}

Notes: "*** p-value < 0.01; ${ }^{* *} \mathrm{p}$-value $<0.05 ;{ }^{*} \mathrm{p}$-value $<0.10$. mot Motivation adjustment apl Application adjustment perf Performance adjustment aenv Academic environment adjustment nsfas NSFAS" 
administrators should take note of the role of perceptions of academic environment in academic performance.

If motivation, according to Baker and Siryk (1999, 14), relates to "attitudes toward academic goals and the academic work required, motivation for being in college and doing academic work, sense of educational purpose" then why is motivation not moderated by ethnicity? Is the assumption made here incorrect, that groups exposed to a history of inequality (Ballard et al. 2006) may be more highly motivated than those that had not? Further analysis was performed. Indeed, according to the full scale items tested, Black students had higher mean motivation as a group (24.21) versus White students (23.72). When a t-test is used to test the significance of differences in means between Black students and the rest of the cohort, the higher mean for Black students is however not found to be significantly different. Given the high motivation required by all students to succeed in accountancy studies it is possible that range restriction may "dampen" these differences. The lack of significance of the moderation testing might reflect this. Further research should extend these tests to other contexts of student performance, as these results may only generalise to accounting contexts (and only to the extent they share similarities with this one).

In terms of group means, Black students also report marginally higher application (13.78 versus 13.75) and academic environment adjustment (14.82 versus 14.5), but lower performance adjustment (24.05 versus 25.72) than White students. When t-tests are performed, the lower mean of Black students on performance adjustment is significantly different from the rest of the cohort $(p<.0001)$, and the higher mean on academic environment is also significant $(\mathrm{p}<.04)$. In contrast, the lower mean of motivation for White students versus the rest of the cohort is significant $(p<.024)$, as is the higher mean for performance $(p<.0001)$.

Although the NSFAS variable might not capture the full effect of disadvantage associated with ethnicity, when it was tested, results suggest that the higher mean motivation of NSFAS students is significantly different from the rest of the cohort $(p<.044)$. NSFAS students have higher mean application, but this is significant at "just outside of the five percent level of significance" $(\mathrm{p}<.062)$, as is their higher mean value of academic environment adjustment $(\mathrm{p}<.058)$. Students experiencing the most socio-economic disadvantage (reflected in NSFAS funding due to its means test) may have higher motivation than their counterparts, might report working harder, and might be more satisfied with the academic environment. Further research should seek to understand how these potential motivational and application advantages might be channelled toward improved performance. For Black students, if fees are paid through NSFAS, academic performance is significantly lower. A means test is required to access NSFAS support, and this variable acts as a useful proxy for financial disadvantage. This result suggests that financial disadvantage may be a channel through which legacy effects constrain 
academic performance. Older students in this group might also be at a disadvantage, as age is negatively related to academic performance. Black women also have significantly higher academic performance than Black men. These associations are not significant for the rest of the cohort.

Table 4 reports the results of the same testing process, but with critical ratio tests of differences between the White student group and the rest of the cohort. This dimension of ethnicity is found to moderate the relationships between academic performance and age as well as whether a respondent accesses NSFAS funding. White students who are older do not seem to face the same challenges as the rest of the cohort, and do not face the same negative association between NSFAS funding and academic performance as the rest of the cohort. White students might be relatively less vulnerable to age effects and the influence of financial disadvantage. There is also little evidence of an association between any of the dimensions of academic adjustment and academic performance for White students. This suggests that academic performance for these students may be less sensitive to differences in academic adjustment. It is thus not possible to rule out legacy effects in their influence on academic performance, at least insofar as these relate to the potential influence of age and financial disadvantage on academic performance. On the basis of these results which provide evidence of moderation, the null hypothesis is rejected and the alternative hypothesis is accepted.

Table 4: Critical ratio tests of moderation (White students)

\begin{tabular}{|l|l|l|c|c|c|c|c|}
\hline \multicolumn{2}{|c}{} & \multicolumn{2}{c|}{ White } & \multicolumn{2}{c|}{ Rest of cohort } & P \\
\cline { 4 - 8 } & \multicolumn{2}{c}{ Estimate } & P & Estimate & P & z-score \\
\hline marks & $<---$ & mot & 15.045 & 0.305 & -5.069 & 0.416 & -1.262 \\
\hline marks & $<---$ & apl & -15.369 & 0.636 & 7.726 & 0.363 & 0.688 \\
\hline marks & $<---$ & perf & 38.197 & 0.600 & -6.093 & 0.488 & -0.603 \\
\hline marks & $<---$ & aenv & -1.601 & 0.760 & 3.150 & 0.049 & 0.866 \\
\hline marks & $<---$ & Age & 1.441 & 0.103 & -0.914 & 0.000 & $-2.567^{* *}$ \\
\hline marks & $<---$ & male & -3.010 & 0.104 & -1.493 & 0.003 & 0.790 \\
\hline marks & $<---$ & nsfas & 22.893 & 0.120 & -1.453 & 0.071 & $-1.652^{*}$ \\
\hline AAMot5 & $<---$ & mot & 1.131 & 0.000 & 1.244 & 0.000 & 0.769 \\
\hline AAApp1 & $<---$ & apl & 0.824 & 0.000 & 0.782 & 0.000 & -0.322 \\
\hline AAPer6 & $<---$ & perf & 3.538 & 0.002 & 1.805 & 0.000 & -1.537 \\
\hline AAPer1 & $<---$ & perf & 0.894 & 0.004 & 0.723 & 0.000 & -0.540 \\
\hline AAEn1 & $<---$ & aenv & 0.940 & 0.000 & 0.704 & 0.000 & -1.286 \\
\hline AAMot6 & $<---$ & mot & 0.756 & 0.000 & 0.827 & 0.000 & 0.478 \\
\hline AAApp2 & $<---$ & apl & 1.301 & 0.000 & 1.067 & 0.000 & -1.291 \\
\hline AAPer5 & $<---$ & perf & 4.139 & 0.002 & 1.882 & 0.000 & $-1.66^{*}$ \\
\hline June & $<---$ & marks & 0.666 & 0.000 & 1.491 & 0.000 & $3.172^{* * *}$ \\
\hline
\end{tabular}

Notes: "*** p-value < 0.01; ${ }^{* *} p$-value < $0.05 ;{ }^{*} p$-value < 0.10. mot Motivation adjustment apl Application adjustment perf Performance adjustment aenv Academic environment adjustment nsfas NSFAS"

The results considered above relate to ethnic subsamples. What relationships then manifest 
across the entire sample? In other words, what relationships would generalise across the entire sample? Although the majority of students are Black, Table 5 offers a perspective of tested associations across the entire sample that might generalise to other populations to the extent that they are similar in characteristics to this one.

According to these results, satisfaction with the academic environment is directly and significantly associated with performance. The implication of this is that performance might be vulnerable to dissatisfaction with the academic environment. Older students are found to perform more poorly than younger students. Male gender is positively associated with performance but this association is weakly significant. These results broadly suggest relationships that might generalise across first year samples in this context, to the extent to which conditions are similar to those of the cohorts under study. However, heterogeneity bias is arguably present, in that there might be different relationships that "work against" each other when sub-samples are combined. The interaction of ethnicity and gender is considered in the following section, in relation to the structural model that was explicitly developed to test this theoretical interaction, given its importance in this context.

Table 5: Standardised regression weights (Full sample)

\begin{tabular}{|c|c|c|c|c|c|c|}
\hline \multicolumn{3}{|c|}{ Parameter } & \multirow{2}{*}{$\begin{array}{c}\text { Estimate } \\
-.102\end{array}$} & \multirow{2}{*}{$\begin{array}{l}\text { Lower } \\
-.269\end{array}$} & \multirow{2}{*}{$\begin{array}{c}\text { Upper } \\
.050\end{array}$} & \multirow{2}{*}{$\begin{array}{c}\mathbf{P} \\
.211\end{array}$} \\
\hline Age & $<---$ & aenv & & & & \\
\hline Age & $<--$ & perf & -.080 & -.905 & .577 & .741 \\
\hline Age & <--- & apl & .078 & -.878 & 1.376 & .806 \\
\hline Age & $<---$ & mot & .138 & -.483 & .649 & .557 \\
\hline marks & $<---$ & mot & -.150 & -1.526 & .237 & .469 \\
\hline marks & <--- & apl & .412 & -.311 & 3.287 & .294 \\
\hline marks & $<---$ & perf & -.191 & -2.106 & .317 & .464 \\
\hline marks & $<---$ & aenv & .176 & .045 & .525 & .039 \\
\hline marks & $<--$ & Age & -.101 & -.161 & -.046 & .015 \\
\hline marks & $<---$ & Gender & .061 & .000 & .128 & .101 \\
\hline AAMot2 & $<--$ & mot & .622 & .588 & .653 & .000 \\
\hline AAMot5 & $<---$ & mot & .710 & .675 & .744 & .000 \\
\hline AAApp3 & $<--$ & apl & .563 & .514 & .609 & .001 \\
\hline AAApp1 & $<---$ & apl & .615 & .576 & .649 & .001 \\
\hline AAPer7 & $<--$ & perf & .384 & .330 & .434 & .000 \\
\hline AAPer6 & <--- & perf & .710 & .677 & .741 & .001 \\
\hline AAPer1 & $<--$ & perf & .321 & .268 & .373 & .000 \\
\hline AAEn4 & $<--$ & aenv & .701 & .638 & .769 & .000 \\
\hline AAEn1 & $<--$ & aenv & .505 & .451 & .562 & .000 \\
\hline AAMot6 & $<---$ & mot & .395 & .350 & .436 & .001 \\
\hline AAApp2 & $<---$ & apl & .642 & .604 & .678 & .000 \\
\hline AAPer5 & $<--$ & perf & .766 & .728 & .803 & .000 \\
\hline April & $<<--$ & marks & .599 & .467 & .713 & .001 \\
\hline June & $<--$ & marks & .918 & .770 & 1.164 & .000 \\
\hline
\end{tabular}

Notes. mot Motivation adjustment apl Application adjustment perf Performance adjustment aenv Academic environment adjustment nsfas NSFAS 


\section{Hypothesis b: Ethnicity moderates the influence of gender on performance}

Figure 2 shows the model that was developed to explicitly test the interaction effect of gender and ethnicity on student performance, with the effect of academic adjustment held constant as a control variable in terms of its influence on academic performance. Tests were performed on the interaction moderation effects of both Black and White ethnicity on the relationship between gender and academic performance. The interaction between Black ethnicity and gender is significant at within the ten percent level of significance $(\mathrm{p}<.071)$. Although weakly significant, this result suggests that Black women have higher marks than Black men. In this model, Black ethnicity was not significantly associated with performance $(p<.319)$ with academic adjustment included as a control variable (and with NSFAS, gender and the interaction term also included as covariates). The interaction effects associated with this model are plotted in Figures 3 and 4.

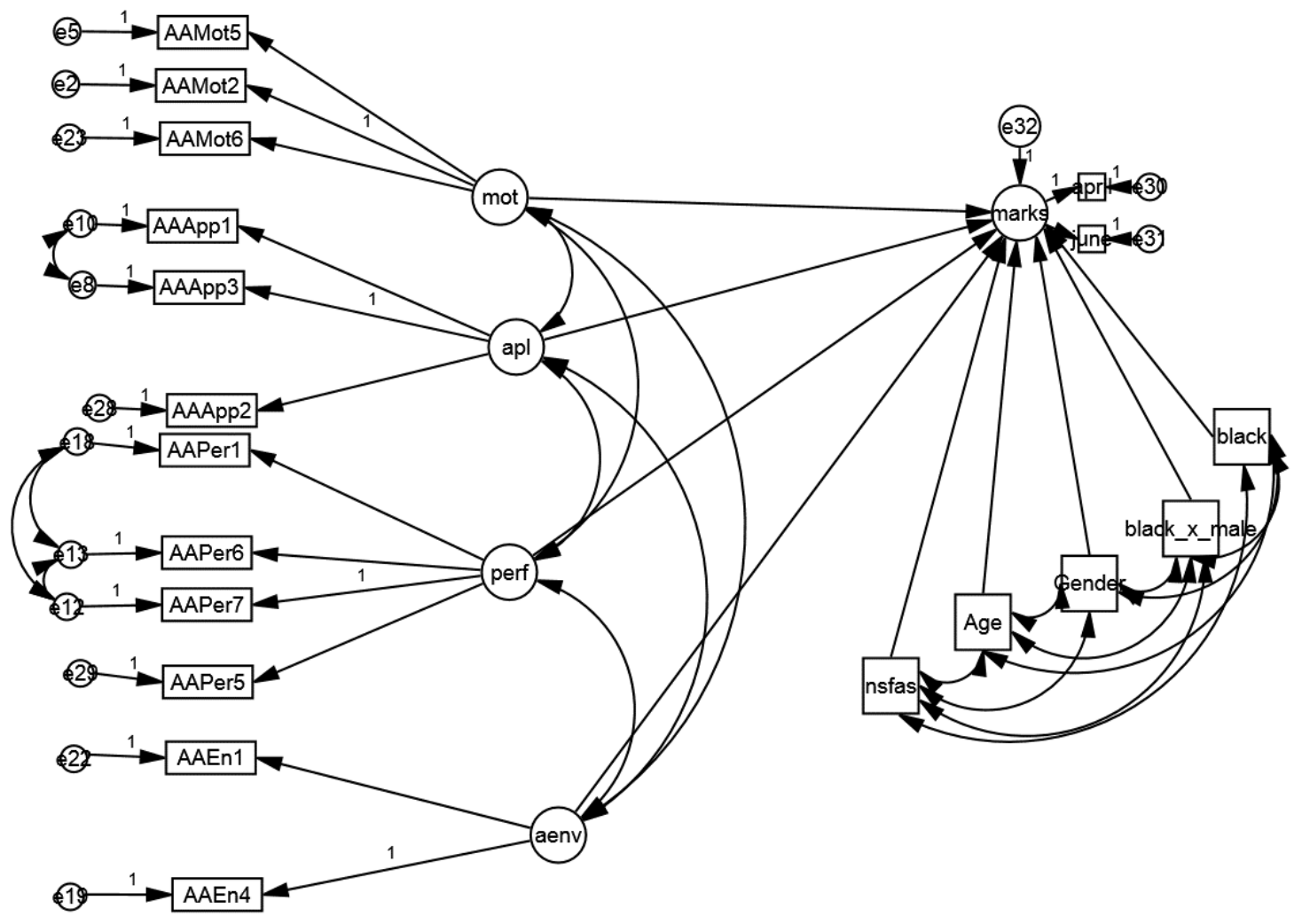

Notes. mot Motivation; apl Application; perf Performance; aenv Academic environment; marks Academic performance

Figure 2: Tests of the moderation (interaction) effect of ethnicity on the relationship between gender and academic performance 


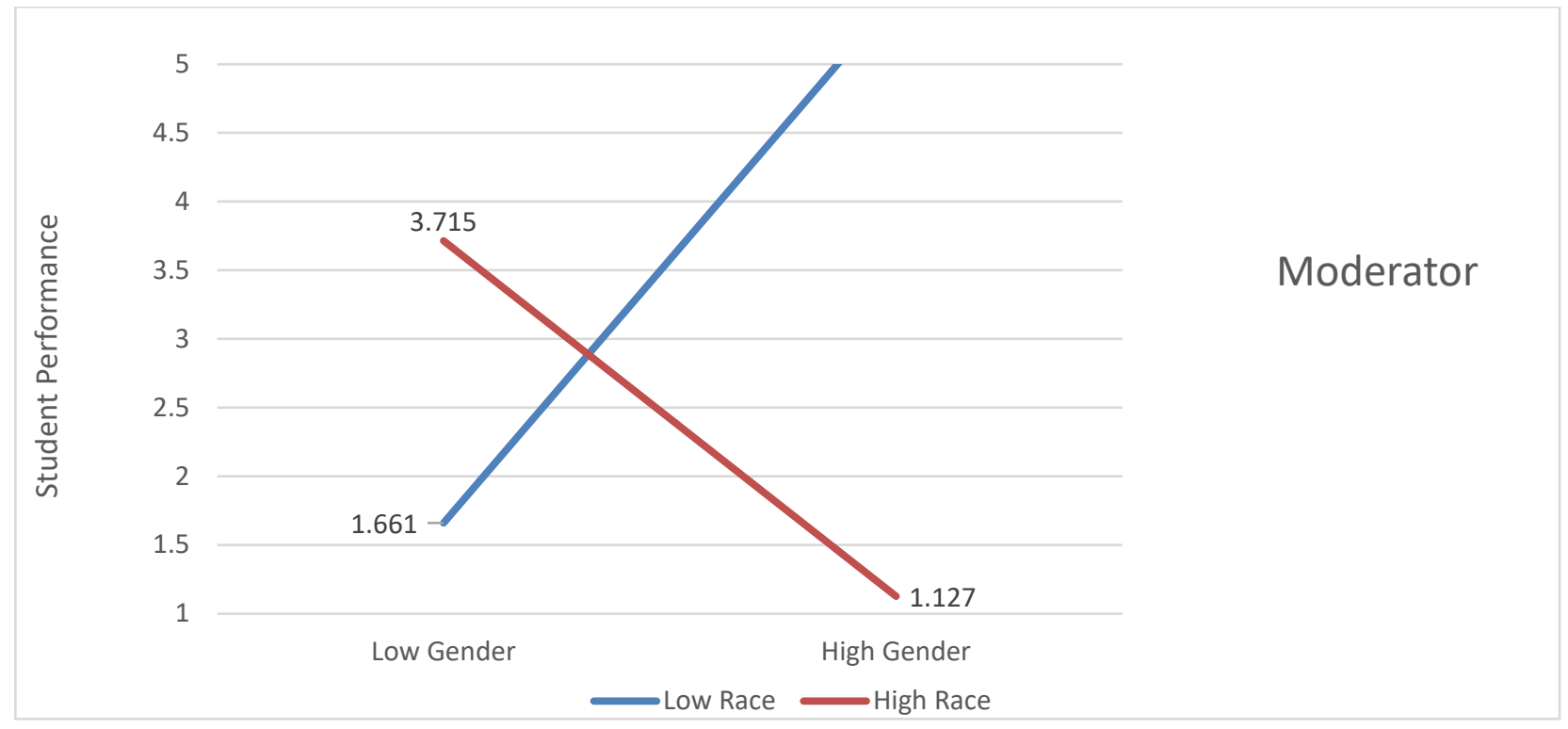

Figure 3: Ethnic moderation of the relationship between gender and academic performance (Black)

According to the interaction plotted in Figure 3, Black (indicated in the diagram as high race as this is 1) women (low gender as this is 0 ) have higher performance than Black men. For the rest of the cohort (all other groups), men have higher performance than women. As previously indicated, however, this interaction effect is weakly significant $(\mathrm{p}<.071)$.

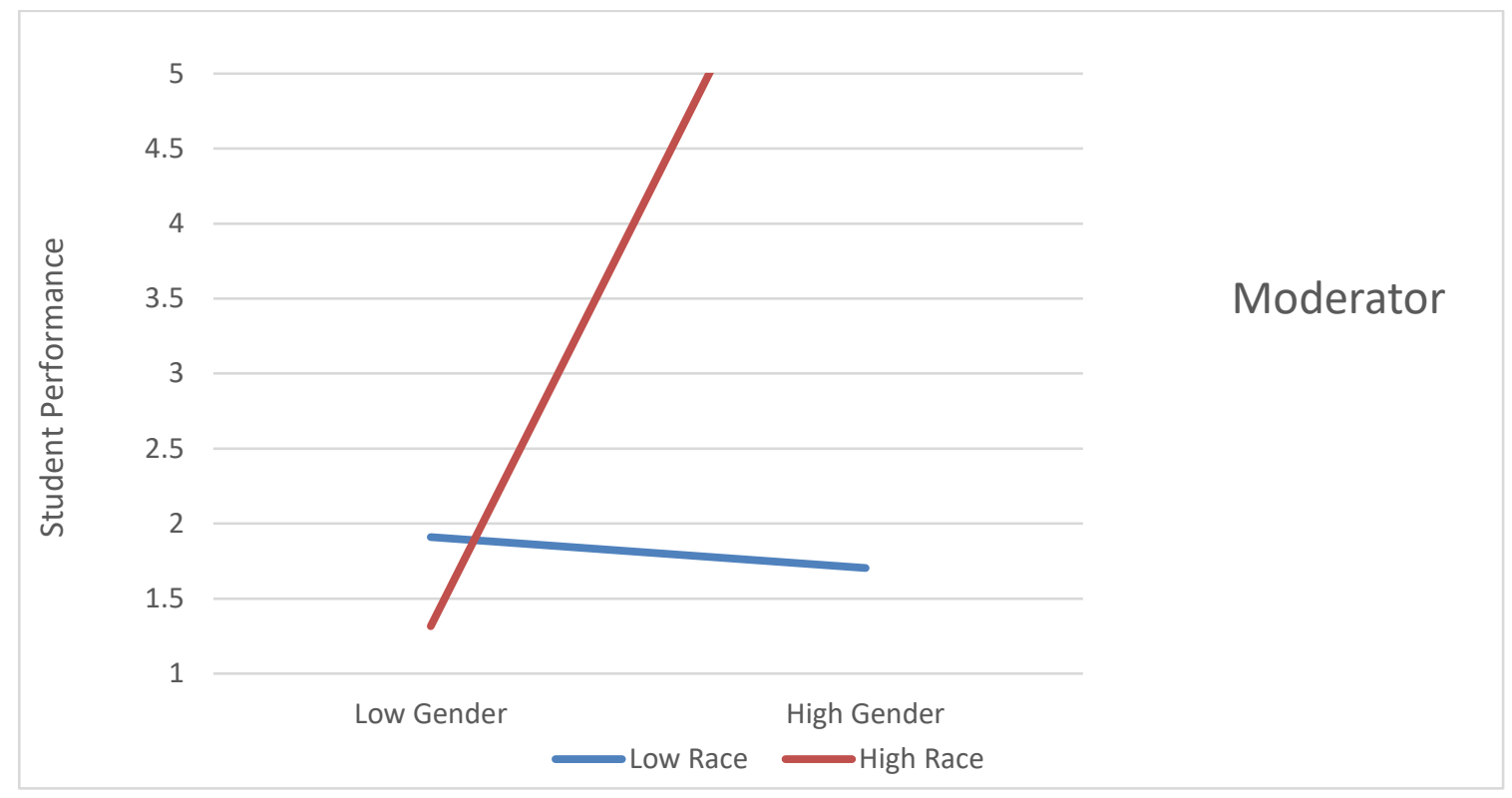

Figure 4: Ethnicity moderation of the relationship between gender and academic performance (White) 
For White students, men have higher performance, but for the rest of the cohort, women have slightly higher performance, although this interaction effect is not significant $(p<.217)$.

\section{Hypothesis c: Age mediates the influence of academic adjustment on performance}

Figure 5 shows the model developed for testing the mediating effect of age on the relationship between academic adjustment and student performance. For the full sample, tests of mediation find that age does not mediate the relationship between student performance and motivation $(p<.418)$, application $(p<.786)$, performance $(p<.674)$, and academic environment $(p<.112)$ dimensions of academic adjustment. These results suggest that the influence of academic adjustment on student performance does not seem to work through age as a channel.

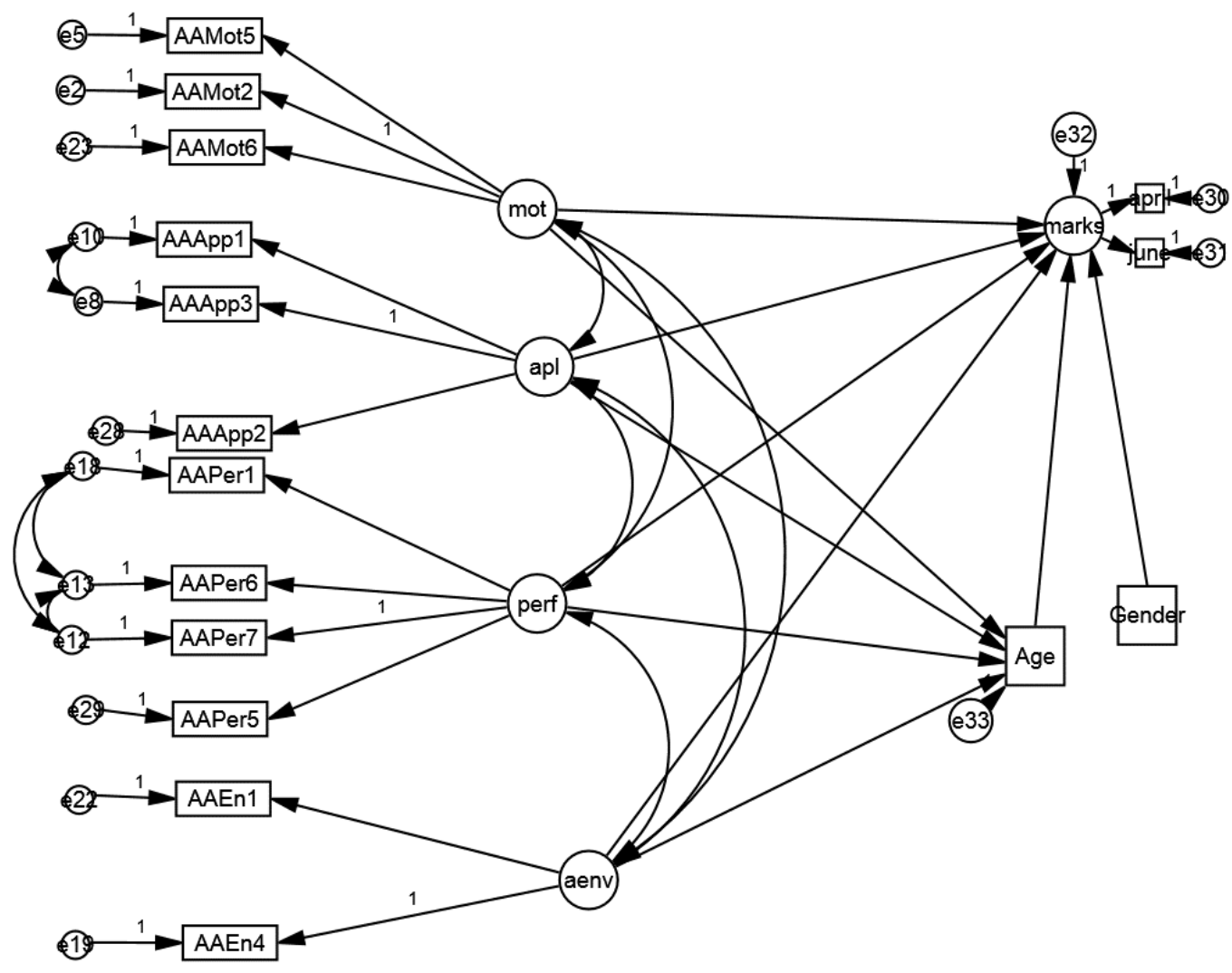

Notes. mot Motivation; apl Application; perf Performance; aenv Academic environment; marks Student performance

Figure 5: Tests of the mediation effect of age on the relationship between academic adjustment and student performance

Despite strong and negative associations between age and academic performance across the sample, age does not seem to act as part of the relationship between academic adjustment and academic performance. The null hypothesis is therefore not rejected, and the alternative 
hypothesis is not accepted.

These results imply that support should be provided for older students, but that this support should not be limited to that related to academic adjustment. Further research in this context should seek to understand why it is that older students perform more poorly in assessments.

Certain important implications arise from these results. The findings here suggest that discriminatory legacy effects persist in the form of financial disadvantage. A more concerted effort is required to support students that are vulnerable to financial disadvantage. NSFAS funding should be supplemented with other forms of support. If academic performance is vulnerable to effects of the academic environment, constant vigilance is required of university administrators, to ensure a more supportive and inclusive university environment.

These findings have further implications for higher education institutions in general across the country, in that financial disadvantage is a shared problem. NSFAS support should be considered in a more holistic way, and more resources should be allocated to support these students in their adjustment to university life. Such investments might increase the effectiveness of the NSFAS programme, and reduce both human and financial costs associated with student drop out and repeated years of study.

These results also imply that the issues raised in the \#FeesMustFall protests, in that they related primarily to student finance and other issues of historical discrimination, should not be disregarded, as they seem to have a basis in these results. All stakeholders in this higher education context should find ways to do more to eliminate these legacy effects. Further studies like this one that identify the persistence of discriminatory legacy effects should be encouraged, as any persistence of these effects is unacceptable. Such knowledge is needed to eliminate these effects. Doing so will ensure a more equitable society.

\section{CONCLUSIONS}

The objective of this article was to test theory that predicts certain relationships between ethnicity, as a proxy for legacy effects associated with South Africa's history, and the contribution of academic adjustment to academic performance in the context of a large South African university. In order to test these theoretical predictions, three structural equation models were developed to represent tests of the requisite theory in each instance. First, ethnicity was tested as a moderator of the relationship between academic adjustment and academic performance. Although no moderation effect was found, perceptions of academic environment were found to be positively associated with academic performance for Black students.

Given that the study coincided with the \#RhodesMustFall and \#FeesMustFall protests of 
2015 and 2016, this result suggests that academic performance can be vulnerable to poorer perceptions of the academic environment for certain students. University administrators should seek to provide more effective support for students who have concerns about the academic environment. A genuine and sincere engagement with these issues might improve the academic performance of vulnerable students by addressing dissatisfaction. The lower levels of performance of NSFAS students suggest that socio-economic disadvantage is a primary constraint to academic performance in this context.

Further research should seek to understand why there is a within-ethnicity gender gap in performance. Age was not found to act as a channel for the workings of academic adjustment and performance, notwithstanding the negative association between age and performance. Given that this association is not significant for White students, it is possible that socioeconomic disadvantage may explain part of this relationship. Overall, these results are taken to suggest that legacy effects of disadvantage persist in this context, and that the associations between academic adjustment and academic performance may act through the academic environment channel in this context. Given the seriousness of the consequences of the student protests of 2015 and 2016, these results should be heeded, and used to inform support interventions for accountancy students in this context. This should go some way toward the ultimate equalisation of opportunity in this context, to the benefit of all.

\section{REFERENCES}

Akenbor, C. O. and E. A. L. Ibanichuka. 2014. Institutional factors influencing the academic performance of students in principles of accounting. International Journal of Higher Education Management (IJHEM) 1(1): 15-26.

Baard, R. S., L. P. Steenkamp, B. L. Frick and K. Kidd. 2010. Factors influencing success in first-year accounting at a South African university: The profile of a successful first year accounting student. South African Journal of Accounting Research 24(1): 129-147.

Badat, S. 2016. Deciphering the South African higher education protests of 2015-16. https://www.sahistory.org.za/sites/default/files/archive-files/dr_saleem_badat_-_the_student_ protests_of_2015-16_final_draft-10march2016.pdf.

Baker, R. W. and B. Siryk. 1989. Student Adaptation to College Questionnaire (SACQ): Manual. Los Angeles: Western Psychological Services.

Baker, R. W. and B. Siryk. 1984. Measuring adjustment to college. Journal of Counselling Psychology 31: 170-189.

Baker, R. W. and B. Siryk. 1999. Student Adaptation to College Questionnaire. $2^{\text {nd }}$ Edition. Los Angeles: Western Psychological Services.

Ballard, R., A. Habib and I. Valodia. 2006. Voices of protest: Social movements in post-apartheid South Africa. Scottsville: University of KwaZulu-Natal Press.

Becker, G. S. 1964. Human capital. Chicago: University of Chicago Press.

Beyers, W. and L. Goossens. 2002. Concurrent and predictive validity of the Student Adaptation to College Questionnaire in a sample of European freshman students. Educational and Psychological Measurement 62: 527-538. 
Boulter, L. T. 2002. Self-concept as a predictor of college freshman academic adjustment. College Student Journal 36: 234-247.

Boyle, R., J. Carter and M. Clark. 2002. What makes them succeed? Entry progression and graduation in computers science. Journal of Further and Higher Education 26(1): 2-18.

Bryman, A. and E. Bell. 2011. Business research methods. $3^{\text {rd }}$ Edition. Oxford: Oxford University Press.

Byrne, B. M. 2010. Structural equation modeling with Amos: Basic concepts, applications, and programming. $2^{\text {nd }}$ Edition. New York: Taylor and Francis Group.

Chansarkar, B. A. and A. Michaeloudis. 2001. Student profiles and factors affecting performance. International Journal of Mathematics Education in Science Technology 32(1): 97-104.

Chaudhuri, A. 2016. The real meaning of Rhodes Must Fall. The Guardian, March 16. https://www.theguardian.com/uk-news/2016/mar/16/the-real-meaning-of-rhodes-must-fall.

Cloete, N. 2015. Fees should not fall for all. https://www.groundup.org.za/article/fees-should-not-fallall_3475/.

Coldwell, D. A. L. and C. W. Callaghan. 2013. The role of internal and external factors on management students' subject choices. South African Journal of Economic and Management Sciences 16(3): 244-257.

Costandius, E., M. Blackie, I. Nell, R. Malgas, N. Alexander, E. Setati and M. Mckay. 2018. \#FeesMustFall and decolonising the curriculum: Stellenbosch University students' and lecturers' reactions. South African Journal of Higher Education 32(2): 67-85.

Gaskin, J. 2016. Structural equation modelling. Gaskination's StatWiki. http://statwiki. kolobkreations.com.

Hickman, G. P., S. Bartholomae and P. C. McKenry. 2000. Influence of parenting styles on the adjustment achievement of traditional college freshmen. Journal of College Student Development 41(1): 41-53.

Jogee, R. N., C. Callaghan and C. W. Callaghan. 2018. Student acculturation in the context of "FeesMustFall". South African Journal of Higher Education 32(2): 122-142.

Jou, Y. H. and H. Fukada. 1995. Effects of social support on adjustment of Chinese students in Japan. Journal of Social Psychology 135: 39-47.

Letseka, M. and S. Maile. 2008. High university drop-out rates: A threat to South Africa's future. Policy Brief. The Human Sciences Research Council (HSRC).

Love, K. M. and D. M. Thomas. 2014. Parenting styles and adjustment outcomes among college students. Journal of College Student Development 55(2): 139-150.

Manjra, S. 2016. GroundUp analysis: Making sense of the students' protests, Their demands and strategies. $e N C A$. http://www.dailymaverick.co.za/article/2016-10-09-groundup-analysis-makingsense-of-the-students-protests-their-demands-and-strategies/\#.WB3kCtJ97IU.

Marburger, D. R. 2010. Does mandatory attendance improve student performance? The Journal of Economic Education 37(2): 148-155.

Meyiwa, T., C. Williamson, T. Maseti and G. Ntabanyane. 2017. A twenty-year review of policy landscape for gender-based violence in South Africa. Gender \& Behaviour: 8607-8617.

Naidoo, N. and L. Nadvi. 2013. Risk factor management and perpetrator rehabilitation in cases of gender-based violence in South Africa. Implications of Salutogenesis. Agenda 27(1): 141-150.

Nel, J. A., V. H. Valchev, S. Rothmann, F. J. R. van de Vijver, D. Meiring and G. P. de Bruin. 2012. Exploring the personality structure in the 11 Languages of South Africa. Journal of Personality 80(4): 915-948.

Ngcoba, Z., C. Manyathela and B. Bateman. 2016. FeesMustFall protests turn violent, bus set alight in Johannesburg CBD. EWN. http://ewn.co.za/2016/10/10/Bus-set-alight-during-Wits-protests.

Nyamayaro, P. C. and C. Saravanan. 2013. The relationship between adjustment and negative emotional states among first year medical students. Asian Journal of social Science and Humanities 2(3): 
270-278.

Ozga, J. and I. Surhanandan. 1998. Undergraduate non-completion: Developing and exploratory model. Higher Education Quarterly 52(2): 316-333.

Papageorgiou, E. and C. Callaghan. 2014. Resource scarcity and information technology: Issues and trends among first-year accounting students. South African Journal of Higher Education 28(5): $1575-1592$.

Papageorgiou, E., C. W. Callaghan, D. A. L. Coldwell and T. Joosub. 2014. Perceptions among professional accounting studies of self, job attractiveness and academic reputation. South African Journal of Accounting Research 28(1): 25-40.

Papageorgiou, E. and C. W. Callaghan. 2017. Parental style and gendered student performance in the South African context of accounting studies. Accounting Education 27(5): 456-478.

Pascarella, E. and P. Terenzini. 1991. How college affects students. San Francisco: Jossey-Bass.

Petersen, I., J. Louw and K. Dumont. 2009. Adjustment to university and academic performance among disadvantaged students in South Africa. Educational Psychology 29(1): 99-115.

Pilane, P. 2016. Whiteness, not Afrikaans, must fall. Mail and Guardian. http://mg.co.za/article/201603-10-whiteness-not-afrikaans-must-fall.

Poplak, R. 2016. Trainspotter: Adam Habib - the rock, the hard place, and the cruel beauty of an uncaring universe. Daily Maverick.

Schmulian, A. and S. Coetzee. 2011. Class absenteeism: Reasons for non-attendance and the effect on academic performance. Accounting Research Journal 24(2): 178-194.

Schreiber, J. B., A. Nora, F. K. Stage, E. A. Barlow and J. King. 2010. Reporting structural equation modeling and confirmatory factor analysis results: A review. The Journal of Educational Research 99(6): 323-338.

Sennett, J., G. Finchilescu, K. Gibson and R. Strauss. 2003. Adjustment of Black students at a historically White South African university. Educational Psychology: An International Journal of Experimental Educational Psychology 23(1): 107-116.

Spaull, N. 2012. Education in SA: A tale of two systems. Keynote presentation at the NAPTOSA Annual Conference, http://www.politicsweb.co.za/politicsweb/view/politicsweb/en/page71619?oid= 323272\&sn=Detail.

Wally-Dima, L., and C. J. Mbekomize. 2013. Causes of gender differences in accounting performance: Students perspective. International Education Studies 6(10): 13-26.

Wheaton, B., B. Muthén, D. F. Alwin and G. F. Summers. 1977. Assessing reliability and stability in panel models. Sociological Methodology 8: 84-136.

Yazedjian, A., M. L. Toews and A. Navarro. 2009. Exploring parental factors, adjustment, and academic achievement among White and Hispanic college students. Journal of College Student Development 50(4): 458-467. 